\title{
https://doi.org/10.48009/2_iis_2006_92-96 \\ RECOVERING TROUBLED PROJECTS: PRESCRIPTIONS FOR SUSTAINED RECOVERY
}

\author{
Douglas Havelka, Miami University, havelkdj@ muohio.edu \\ T.M. Rajkumar, Miami University, rajkumtm@muohio.edu
}

\begin{abstract}
A field study was performed to identify prescriptions for the sustained recovery of troubled information systems development (ISD) projects. The purpose of the study is to identify prescriptive actions that organizations can take to begin to recover troubled projects. Based on a framework for recovery proposed in prior research, this study focuses on one stage of the recovery process, i.e., the "Sustained Recovery" stage. The study is significant for business managers and ISD project managers dealing with the project management process as well as to IS researchers attempting to better understand the ISD process. The output of this effort, to date, is a set of suggested prescriptive actions that project managers, teams, and other stakeholders should consider once a project has been identified as being "in trouble."
\end{abstract}

Keywords: Systems Development, Troubled Projects, Recovery, Project Management

\section{INTRODUCTION}

Troubled projects have been defined as those that are $30 \%$ over schedule or $30 \%$ over budget and have an end product that does not meet the users' specifications [7]. Several researchers have identified issues surrounding troubled projects, including runaway projects [3], de-escalating commitment to projects [4], habitual trouble in software development [6], getting projects back on track [5], and saving troubled projects [2]. Despite this attention from researchers, it is still difficult and sometimes impossible to turn a project around once it has been identified as being in trouble.

This research study is one phase of a research project aimed at fleshing out the Framework for Troubled Project Recovery proposed by prior research [1]. The framework is presented in Figure 1 and is composed of four stages: Recognition, Immediate Recovery, Sustained Recovery, and Maturity. Each of these stages is broken down into a set of steps to successfully achieve each stage.

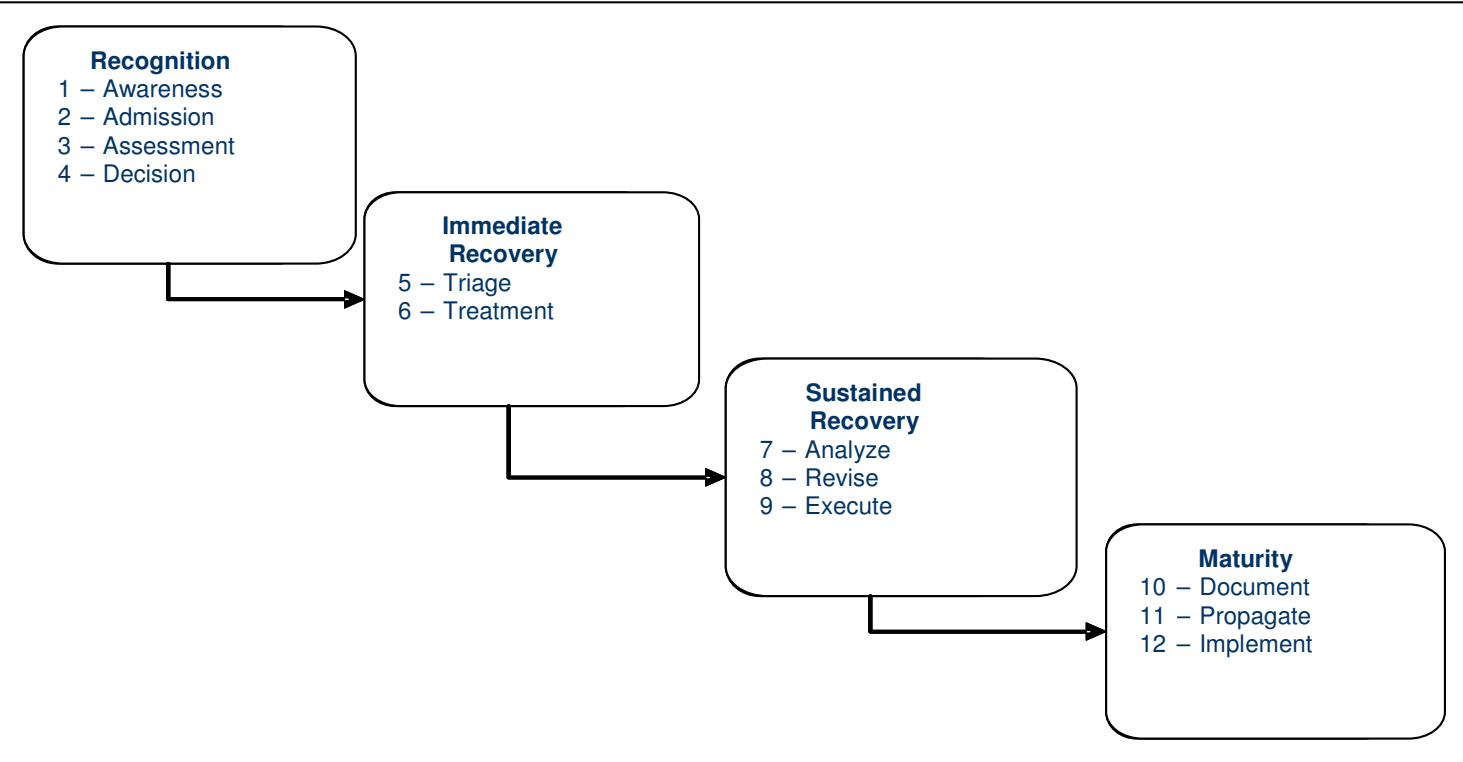

Figure 1. The Staged Framework for the Recovery of Troubled IS Development Projects 
The Recognition stage focuses on problem identification. Before any project can be recovered, the fact that the project is in trouble must be recognized. Once the trouble is recognized, peer counsel and advice is often sought out and the problem is communicated to management and other stakeholders. A decision to recover (or abandon the project) is then made and the recovery process begins.

In the Immediate Recovery stage, steps are taken to nurture the troubled project back to stability. The aim in immediate recovery is to identify and isolate the critical problems and take immediate corrective or mitigating action. The aim is not to revamp the complete plan.

Once the project is in a stable state, the long-term or Sustained Recovery stage can be put in motion. The steps include analyzing the project status and creating an issue list with resolutions for addressing the issues, creating a revised baseline plan and obtaining management approval, followed by executing and monitoring the revised plan.

The final stage in the recovery framework is Maturity. The maturity stage focuses on leveraging the lessons learned from recovery of a project and communicating this throughout the organization.

The goal of this study was to identify an initial set of prescriptive actions that project managers or other stakeholders might take for the Sustained Recovery stage of the framework.

\section{THE SUSTAINED RECOVERY STAGE}

The Sustained Recovery stage of the framework is composed of three steps: Analyze, Revise, and Execute.

\section{Analyze Status}

Based on the prior stages, there should be an initial inventory of issues that need to be attended. To further identify issues for this list, generic analysis techniques could be used such as problem analysis, root-cause analysis, or gap and risk analysis. If an issue cannot be resolved at the project management level, a plan for escalation of the issue to higher management must be put into place, along with alternative options to mitigate the risks associated with the issue.

\section{Revise \& Approve}

The actions needed to get the project back on track need to be incorporated into the original plan or a new plan for the project must be developed. The new plan must then be approved by upper level management and other stakeholders, i.e., clients. This might involve adjustments in scope, reprioritization of goals and objectives, and clarification of the objectives and expectations. A re-estimation of tasks may be performed, a new schedule will be drawn up, and resources allocated to the project accordingly.

In addition, training in new technologies must be provided to team members if needed. The risks involved in the project should be re-evaluated and plans for mitigating the risk must be established and evaluated. In essence, a complete new baseline plan is drawn up. This revised plan and milestones becomes the metric against which success for the project is now measured. Changing project managers is a common resolution in software development firms as well as the addition of internal experts, technical or functional, to the project team.

\section{Execute and Monitor Plan}

After the revised baseline is established and approved, the plan should be implemented and the status of the project must be continually monitored. Implementing the plan may include adding or redeploying resources. This may be human resources that may involve re-assigning, refocusing, or removing personnel on the team. Or, other project resources such as software development tools or equipment may need to be purchased or changed in some manner.

\section{RESEARCH METHODOLOGY}

To verify whether the Sustained Recovery stage of the recovery framework is composed of the three steps (analyze, revise, and execute), a field study was performed to determine what actions IT development groups actually performed once a project had reached the Sustained Recovery stage. The field study consisted of a series of four focus groups. Each group met for approximately 60-90 minutes. The protocol followed for the focus groups was composed of five steps:

Step 1: The purpose of the focus group and the desired outcomes are presented. A short description of the process being used for the focus group is given. A definition of troubled projects and some of 
the indicators found in prior research for identifying troubled projects are presented and explained. The question to be answered is presented.

Step 2: The participants are asked to silently and individually jot down all ideas that come to their minds with regard to the question being asked for 5 minutes on a worksheet.

Step 3: Each manager is asked to state one of their ideas in a round robin fashion. Ideas will be put up on the wall. The participants are encouraged to feed off of others' ideas and add to their lists. The listing continues until all the ideas from each participant is listed

Step 4: Each of the listed ideas is discussed for clarification and for understanding.

Step 5: Wrap up \& collection of background data such as length of experience in industry, length of project management experience and number of troubled projects worked on will be gathered.

The focus groups were all conducted during one summer from companies performing software development work in India. The organizations were from different areas of the country and developed different types of software products. All the organizations have obtained a Capability Maturity Level of 4, indicating a high level of development process maturity and sound management policies. The demographics of each group are presented in Table 1.

The question put to the focus groups was

"What long term measures do you take once a project is determined to be in trouble?"

This question was framed by first asking the participants to think of troubled projects that they had encountered in the past. The subjects were asked to generate as many items as they could. Once all the items had been listed the group was asked to discuss and help define these items.

\section{RESULTS}

The overall outcomes of the focus groups provided 113 total items suggested as sustained or long-term prescriptions for troubled project recovery (Group 1 had 18, Group 2 had 35, Group 3 had 24, and Group 4 had 36). Within these 113 items, there were some similarities among items from different groups and from different members within the same group.
However, the meanings and intent were nuanced enough to be considered semantically different.

Table 1 shows the number of prescriptions given by each group for each of the sub-stages of the recovery framework. Overall, there were 30 prescriptions suggested that fell into the Analyze sub-stage as presented in Table 2, 55 in the Revise sub-stage as presented in Table 3, and 28 in the Execute sub-stage as presented in Table 4 (Tables 2, 3, and 4 are available from the authors upon request).

Table 1. Focus Group Demographics

\begin{tabular}{|l|l|l|l|l|}
\hline Group & I & II & III & IV \\
\hline Number of participants & 7 & 9 & 5 & 17 \\
\hline $\begin{array}{l}\text { Average project } \\
\text { management experience } \\
\text { (years) }\end{array}$ & 6 & 5.5 & 3 & 5.5 \\
\hline $\begin{array}{l}\text { Average industry experience } \\
\text { (years) }\end{array}$ & 15 & 10.3 & 9.6 & 9.9 \\
\hline $\begin{array}{l}\text { Total number of } \\
\text { prescriptions identified }\end{array}$ & 18 & 35 & 24 & 36 \\
\hline $\begin{array}{l}\text { Number of Analysis } \\
\text { prescriptions identified }\end{array}$ & 4 & 8 & 3 & 15 \\
\hline $\begin{array}{l}\text { Number of Revise } \\
\text { prescriptions identified }\end{array}$ & 5 & 19 & 15 & 16 \\
\hline $\begin{array}{l}\text { Number of Execute } \\
\text { prescriptions identified }\end{array}$ & 9 & 8 & 6 & 5 \\
\hline
\end{tabular}

\section{DISCUSSION}

Based on the Staged Framework for Recovery, the analysis sub-stage of the sustained recovery stage should focus on "analysis" type of activities. Based on the results of our focus groups and categorization of the prescriptions suggested, 30 of the prescriptions were analytical in nature: this represents approximately $25 \%$ of the total.

Of the prescriptions suggested, a clear majority of these (16 out of 30) are related to project management, e.g., capture and log time lags, identify task dependencies, and review project status with steering committee. This would suggest that the some of the project management "best practices" were not being performed prior to the identification of trouble or were not being performed adequately. This emphasizes the importance of establishing and monitoring project management standard (best) practices for IS projects.

The other prescriptions were focused on improving communication among the team and with the client 
and other stakeholders (9 prescriptions), better understanding and defining the domain or business objective of the development project (7 prescriptions), improving the relationship and interactions with the client (3 prescriptions), and one (only one) addressing personnel attrition.

For the Revise sub-stage, several themes are present in the prescriptions suggested. First, there is again a focus (22 of 55 prescriptions) on establishing and improving the project management of the project and the techniques/methods being used for development, e.g., adding additional testing, reworking the project schedule, and identifying and tracking issues are all suggested prescriptions.

In addition, there appears to be a focus on human resources or personnel issues during the revise substage. Fifteen of the 55 prescriptions suggested in this sub-stage deal with personnel assignments or development of human resources, e.g., switching tasks based on skills, adding functional consultant experts, and improving motivation by job rotation. A significant subset of the human resource prescriptions were oriented toward training including training on the development process, soft skills, training materials, and team training. The existence of these prescriptions during the revise sub-stage suggests that this may be an area where there is a lack of wellqualified and experienced IT personnel or that the stereotype of the IT specialist lacking people, communication, and team skills may have some basis in fact. Regardless, it would appear that additional and enhanced skills are required during the revise sub-stage.

The importance of establishing and maintaining a good relationship with the client is also present in the revise stage (12 prescriptions). Most of the prescriptions appear to address issues related to working with the client and clarifying the responsibilities of the client and the development team, i.e., planning for dependencies, revised commitments, getting approvals.

There were seven (7) prescriptions in the revise substage related to improving the understanding of the requirements or the documentation related to the requirements, e.g., creation of knowledge artifacts. The primary concept being that the documentation of the requirements needs to be clear to manage and measure the work performed and to avoid scope problems.

Several of the prescriptions (5) were related to communication, again mostly dealing with the client and establishing the mechanisms for clear and timely communication, e.g., single point of contact, changing the structural interface to customer.

In the Execute sub-stage, 28 prescriptions were suggested. There are clear themes in the prescriptions: 1) team management and motivation and 2) obtaining client approval of work. Again, the greatest number of prescriptions (12) suggested is for project management related items, i.e., follow coding standards, perform walkthrough at every milestone. However, these prescriptions have a change in tone; they seem to be much more oriented towards ensuring quality than the prescriptions in the prior sub-stages.

Related to this, it appears that the prescriptions suggested related to the client (11) are all focused on gaining the client's final approval of the work product, e.g., regular follow-up with the customer and approvals. These prescriptions emphasize the importance of gaining (re-gaining) the client's trust once the sustained recovery is underway, i.e., being executed.

In addition to the project management and clientrelated prescriptions suggested for the execute substage, a significant number of the prescriptions focus on managing and motivating the team and keeping their morale up, e.g., motivate team for improved productivity. This theme highlights the importance of implementing some of the human resource development and personnel decisions from the last sub-stage during the execution sub-stage to achieve success.

\section{CONCLUSIONS}

Overall, it appears that the data support the proposition that the sustained recovery stage of the framework is composed of three separate sub-stages. The type of activities performed and the targets of these activities appear to be different in the three substages.

Based on the observations made in the discussion section of this paper, we propose the following higher level prescriptions that appear to be the most important in each of the three sub-stages:

\section{Analyze:}

- Determine which project management best practices to implement for the project. 
- Determine where communication breakdowns occurred.

- Re-evaluate the business purpose and value of the project and define what would be successful outcomes.

\section{Revise:}

- Establish the project management best practices to be used going forward.

- Obtain and re-assign personnel to maximize the effectiveness of the team.

- Immediately implement training or re-training for critical skill shortage, or deficit, areas.

- Establish the mechanisms for communication with the client and among the team members.

- Review the business content and specific requirements for the project (based on the reevaluation done earlier).

- Establish clear responsibility for documenting work products as they meet specifications.

\section{Execute:}

- Perform and monitor the project management best practices, especially quality assurance and signoffs from the client.

- Be pro-active to inform and to gain approval from the client as work is undertaken and completed.

- Pay attention to the morale and motivation of the team. Reward performance and correct inefficiencies.

While these prescriptions seem to make logical sense, even common sense, we cannot make any claims regarding their actual efficacy. We did not perform any type of validation testing to determine which, if any, of these prescriptions are effective (or not) or the level of their impact on project quality, cost, time, or work product. We suggest that these questions are opportunities for future research.

To conclude, a field study using focus groups of IT development professionals was used to validate the sub-stages of a troubled IT projects recovery framework. In general, the data obtained support the proposed sub-stages of sustained recovery: analyze, revise, and execute.

\section{REFERENCES}

1. Aiyer, J., Rajkumar, T. M. \& Havelka, D. (2005). A staged framework for the recovery and rehavilitation of troubled IS development projects. Project Management Journal, 36(4), 32-43.

2. Feldman, J. (2001). Project recovery: Saving troubled projects. Information Strategy, 17(2), 611.

3. Glass, R. L. (1998). Software Runaways. Upper Saddle River, NJ: Prentice Hall.

4. Keil, M. \& Robey, D. (1999). Turning around troubled software projects. An exploratory study of the de-escalation of commitment to failing courses of action. Journal of Management Information Systems, 15(4), 63.

5. Partlow, J. \& Wynes, D. (2002). Teamwork puts a troubled project back on track: A case study in relationship building. Information Strategy-The Executive's Journal, 18(2), 12-22.

6. Tarek, A. M. \& Madnick, s. (1990). The elusive silver lining: Howe we fail to learn from project management failures. Sloan Management Review, 39-49.

7. Whittaker, B. (1999). What went wrong? Unsuccessful information technology projects. Information Management and Computer Security, 7(1), 23-29. 